\title{
Rosario Castellanos, un saber del alma
}

\section{Graciela Hierro}

\author{
Para Gabriela Cano
}

\begin{abstract}
No, no es la solución tirarse bajo un tren como la Ana de
Tolstoi, ni apurar el arsénico de Madame Bovary, ni aguardar en los páramos de Ávila la visita del ángel con venablo, antes de liarse el manto a la cabeza y comenzar a actuar. Debe haber otro modo que no se llame Safo, $n i$ Mesalina, ni María Egipciaca. Otro modo de ser humano y libre. Otro modo de ser.

"Meditación en el umbral", Rosario Castellanos
\end{abstract}

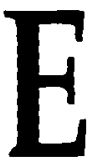

n la búsqueda de otro modo de ser, Rosario Castellanos se pregunta "Existe una cultura femenina?", abriendo la cuestión que otra famosa mexicana habia dejado en el aire tres siglos antes: sor Juana Inés de la Cruz, también filósofa-poeta, en su texto "La respuesta a sor Filotea". 'Ambas utilizaron el análisis filosófico y la poesía como medios para reflexionar sobre el ser y el hacer del géncro.

Es interesante destacar otro paralelo entre filósofas, ahora Simone de Beauvoir y la mexicana Castellanos. La tesis de Castellanos "Sobre cultura femenina", para obtener su maestría en filosofia en $1950,{ }^{2}$ presenta una curiosa similitud con $E l$ segundo sexo de Simone de Beauvoir. En ambas autoras aparece una resistencia inicial de involucrarse en temas femeninos; repugnancia que las dos atacan con el mismo recurso que para mí es propio de la filosofia y literatura feminista: la ironía. A este rasgo me referiré más adelante en el epílogo. Beauvoir dice: (estos temas son) "irritantes [...] básicamente para las mujeres", Rosario comenta: "Esta interrogación parece, a primera vista, tan superflua y tan conmovedoramente estúpida como aquella otra que ha dado también origen a varios libros y en la que destacados oficia-

' Sor Juana Inés de la Cruz, "Sor Filotea de la Cruz", en Obras completas, t. IV México, FCE, 1976.

2 Rosario Castellanos, Sobre cultura femenina. Tesis. México, UNAM, FFYL, 1950. 
les de la armada británica se preguntan, con toda la seriedad inherente a su cargo, si existe la serpiente marina". ${ }^{3}$

También coinciden en su visión total del universo masculino; Simone afirma: "El mundo siempre ha pertenecido a los hombres" y Rosario concluye que el mundo del que la mujer está excluida es el de la cultura.

Ya entrando en la obra de Rosario Castellanos, Sobre cultura femenina vemos que el análisis de ésta encierra tres cuestiones básicas: la primera, acerca de la contribución femenina a la cultura. Es decir: si existen obras artísticas, investigaciones científicas o realizaciones éticas escritas por ellas. La segunda se plantea por qué la contribución femenina a la cultura del hombre ha sido tan escasa y, finalmente, si en verdad se puede hablar de un tipo específico de contribución femenina a la cultura, la cultura femenina. Esta es la cuestión que a mí me interesa desarrollar en esta comunicación y precisamente argumentar que esta "cultura femenina" es el antecedente de los estudios de mujeres o estudios de género; en segundo lugar que sólo podemos entrar a la filosofia del hombre ${ }^{4}$ integrando una corriente de cultura femenina-feminista, y por último si en esta corriente feminista se integra -entre otras-: "un saber del alma", como llama María Zambrano a su filosofar. Destacando así un último paralelo entre pensadoras, en este caso entre la filósofa mexicana y la española, lo que me permite encontrar una línea de continuidad entre filósofas poetas.

\section{Rosario Castellanos: "un saber sobre el alma"}

Aparecen aquí, en su germinación, esas dos formas de razón -la mediadora y la poética-. que han guiado todo mi filosofar, si es que ha sido asi, filosofar, pues signo ha sido de mi vida el someterme a la prueba de la renuncia de la filosofia...

María Zambrano. Hacia un saber sobre el alma.

Deseo conocer si el filosofar femenino trata de un saber teórico (capaz de ser expuesto y discutido ante las asambleas de los que trabajan la "ciencia dura"); o es un saber "sobre el alma" como bellamente María Zambrano

\footnotetext{
${ }^{3}$ Se refiere al libro de T. E. Gould, The Case of the Sea Serpent. Editado en español en La Habana, Cuba, 1948.

${ }^{4} \mathrm{Cf}$. Andrea Nye, Feminist Theory and the Philosophies of Man. Routledge, Chapman and Hall, 1988. En este texto se discute la historia de la filosofía occidental y su relación con la teoría feminista.
} 
llama a la mezcla feliz de razón y sentimiento, que sólo a las almas "femeninas" compete. Conste que las "almas femeninas" pueden pertenecer a cualquier género.

El camino que sigo tiene dos etapas. La primera se detiene en Rosario Castellanos y su cuestionamiento acerca de la cultura femenina. Terminado el diálogo con la filósofa mexicana continuaré --más tarde-- la marcha para encontrar a María Zambrano y su razón poética.

La pregunta es: "Existe una cultura femenina? Recordemos que esta interrogación parece, a primera vista, tan superflua y tan conmovedoramente estúpida como la de la serpiente marina. Ambos problemas al parecer tan distantes: cultura y serpientes, parten de un mismo origen: un rumor, antiguo y pertinaz, utilizando para ello la validez de los testimonios en pro y en contra de las hipótesis afirmativas. Que la serpiente marina ha sido vista (aunque las descripciones no coinciden); que existen mujeres cultas también ha sido sostenido por algunos. Sin embargo, concluye Rosario:

[...] un coro de hombres cuerdos que permanecen en las playas y desde alli sentencian la imposibilidad absoluta de: que monstruos tan extraordinarios, como has serpientes marinas y las mujeres cultas o creadoras de cultura, sean algo más que una alucinación, un espejismo, una morbosa pesadilla. ${ }^{5}$

Dejando a un lado a la marina británica y sus preocupaciones, Rosario procede a "perseguir la otra quimera". Advierte que en "las filosofías del hombre" desde la clásica griega hasta las contemporáneas, este problema ya ha sido ampliamente tratado. Castellanos no se arredra ante el problema y lee las opiniones más pesadas de Schopenhauer, Weininger y Simmel. Las conclusiones a las que llegan los ilustres doctores son de sobra conocidas por nosotras, de modo que no vale la pena entrar en el detalle de las mismas. Más interesante para el tema que nos ocupa es conocer la crítica que de éstas emprende Rosario. Comienza advirtiendo que las críticas -por parte de las pensadoras- son "impracticables si no se tiene una base sólida, un punto seguro desde el cual partir. $Y$-continúa- para establecer este punto no queda más remedio que recurrir a la propia tentativa, a la propia labor, al propio hallazgo". "Esta es naturalmente la perspectiva del género, aunque aún no tome ese nombre.

5 Rosario Castellanos, Sobre cultura femenina. México, Ediciones de América/ Revista Antológica, 1950, p. 11.

${ }^{6}$ Ibid., p. 28. 


\section{La perspectiva del género}

Como todos los métodos utiliza primero la vía crítica: Rosario analiza la validez de la descripción del principio femenino expuesto por la filosofia del hombre. Vemos que la esencia del género a juicio de los doctores, está basa$\mathrm{da}$, como ya sabemos, en rasgos negativos cuidadosamente consignados en las filosofias históricas y da como resultado a priori, la "esencia femenina" que nos cierra la puerta por la que

[...] ellos holgadamente atraviesan para desembocar en un mundo luminoso, sereno, altísimo, [...] incomparablemente mejor que el que yo habito [...] El mundo que para mí está cerrado tiene un nombre: se llama cultura. Sus habitantes son todos ellos del sexo masculino. Ellos se llaman a si mismos hombres y humanidad a su facultad de residir en el mundo de la cultura y de aclimatarse en él. Si le pregunto a uno de esos hombres qué es lo que hacen él y todos sus demás compañe. ros en ese mundo me contestará que muchas cosas: libros, cuadros, estatuas, sinfonías, aparatos, fórmulas, dioses [...] Ahora, si le pido permiso para entrar, me lo negará $[. .$.$] Yo [\ldots]$ me retiraría con docilidad y en silencio. Pero me quedaria pensando, no en la injusticia ni en la arbitrariedad de esa exclusión aplicada a mí y a mis compañeras de sexo (en verdad no deseaba tanto entrar, era una simple curiosidad) sino en que entonces no entiendo [...] cómo es que existen libros firmados por mujeres, cuadros pintados por mujeres, estatuas [...] ¿Cómo lograron introducir su contrabando en fronteras tan celosamente vigiladas? Pero sobre todo ¿qué fue lo que las impulsó de modo tan irresistible a arriesgarse a ser contrabandistas??

Lo que desea saber Rosario es aquello que las impulsó para separarse del rebaño $e$ incursionar en el terreno prohibido superando su propia esencia. Para responderse hay necesidad de continuar con el propio método: recurrir ahora, a la vía lógica. iAh!, entonces comienza el verdadero problema, porque Rosario afirma que no esta acostumbrada a pensar conforme a sus cánones, y así dice: "mi mente femenina se siente por completo fuera de su centro cuando trato de hacerla funcionar de acuerdo con ciertas normas inventadas, practicadas por hombres y dedicadas a mentes masculinas". Habrá entonces -me pregunto- un modo de pensar específico de nosotras, si es así ¿cuál es éste? Los más venerables filósofos también hablan, respecto

${ }^{7}$ Ibid., p. 32. 
del género femenino, de una "intuición directa, oscura, inexplicable y, generalmente, acertada". "Pues bien -responde Rosario-me dejaré guiar por mi intuición. Sin que pretenda universalizarla, aunque sí justificar la actividad cultural de ciertas mujeres [...]" ${ }^{\prime 8}$ concluye la filósofa. Pero antes veamos que cosa puede entenderse por cultura.

\section{La cultura}

En el mundo de la cultura todo tiene que hacerse, que crearse y mantenerse por el esfuerzo. El que hacen los hombres en virtud de aptitudes específicas, que obedecen a reglas y se vierten en moldes detcrminados. Todo esto es la conducta masculina (ellos ta llaman humana). Rosario Castellanos observa que le parece un despliegue de energia inútil, tonto y sin sentido, si se ignora cuales sean los fines que ellos persiguen y sobre todo, qué móviles empujan a la conducta masculina a perseguirlos. La cultura es vista por Castellanos como la vía de la trascendencia ya que es: "la creación de la actividad humana cuando ésta se dirige conscientemente hacia los valores". 9 por su parte, los valores para ser alcanzados, determinan y exigen una conducta especial, ética, que mueve el espíritu. Porque la elevación sobre las circunstancias es privilegio del espíritu. Diferente del intelecto y del instinto. Caracteriza Castellanos al espíritu como una forma de conocimiento, un modo de conducta al servicio de la vida. Es la conciencia de la limitación, la temporalidad y la muerte y el intento humano de superarlas. "El espíritu es un arco tendido hacia el futuro. Vivir espiritualmente, concluye Castellanos es vivir en esta tensión [...] hurgar en él es descubrir la muerte y también tratar de evitarla". ${ }^{10}$ La eternidad es el único clima donde el espíritu puede florecer y tornarse fecundo, la encuentra sólo en los valores y la imita imper fectamente en la cultura. En este momento quiero destacar que el concepto de cultura que maneja Castellanos es semejante a la "razón poética, saber del alma" que ofrece Zambrano. "La razón poética y su metodología particular se hace cargo de la existencia plena del hombre, de su individualidad, de su cuerpo, de su esfera afectiva, sentimental, de su anhelo de trascendencia [...]" Continúa el análisis Castellanos, advirtiendo que "El espíritu, al servirse del cerebro, hace instrumento suyo todo el cuerpo. Y si decimos cuerpo

${ }^{8}$ Ibid., p. 33.

${ }^{9}$ Ibid., p. 39.

${ }^{10}$ Ibid., p. 73

1 Alcira Bonilla, "Razón poética y género: arquetipos femeninos". Comunicación personal de la autora, p. 10. 
decimos sexo -en nuestro caso- cuerpo de mujer; es lícito, por tanto, hablar de un espíritu masculino y otro femenino". ${ }^{12}$ Y la cultura es propia del espíritu masculino.

Aunque, advierte Rosario Castellanos, podrían darse dos circunstancias que dependieran exclusivamente del género femenino, y que explicaran la ausencia de la creación femenina, como las siguientes: 1. La incapacidad específica de las mujeres (que deja sin aclarar por qué algunas mujeres excepcionales sí son capaces de crear cultura). 2. "La falta de atracción que la cultura ejerce sobre lo femenino, en circunstancias comunes y corrientes, pero que variando las circunstancias puede desaparecer y convertirse entonces la cultura en una fuerza atractiva a la que la mujer resulta susceptible de responder, como las mujeres que sí han hecho cultura" ${ }^{13}$ Esta segunda línea de investigación la lleva a reflexionar sobre el espíritu femenino.

\section{El espiritu femenino}

Definido el espíritu, como lo ha hecho Castellanos, "como una conciencia de la limitación, la temporalidad y la muerte y como una actividad salvadora orientada hacia los valores y plasmada en la cultura hablamos, casi sin excep. ciones, de espíritus masculinos". ${ }^{14}$ Él es -nos dice la autora. Todo lo demás está sujeto a su dominio y depende de su habilidad: las cosas, los animales, las mujeres. Ellas, expulsadas del mundo de la cultura, como Eva del paraíso, no tienen más recurso que portarse bien, es decir, ser insignificantes y pacientes, esconder lds uñas como los gatos. Con esto probablemente no vayan al cielo, y además no importa, pero irán al matrimonio que es un cielo más efectivo e inmediato. La incapacidad o la poca inclinación de la mujer por la cultura puede derivar de dos causas: o bien de la falta de percepción de sus limites y de su condición temporal y moral o bien de la falta de medios para la superación de esos límites y condiciones. La primera opción es obviamente falsa, la mujer advierte su limitación y una vez advertida se siente afectada por ella y trata de ensancharla. Ella tiene la conciencia de la muerte. Y las mujeres, afirma Rosario Castellanos, se apegan a la vida muchísimo más que cualquier hombre. Pueden huir del peligro sin el temor de sentirse cobardes. Rara vez inmolan su existencia individual en los altares. Ifigenia es siem. pre sacrificada por su padre. La segunda hipótesis también es falsa: las mujeres son altamente sensibles a los valores.

\footnotetext{
${ }^{12}$ R. Castellanos, Sobre cultura femenina, p. 76.

13 Ibid., p. 34.

${ }^{14}$ Ibid., p. 79.
} 
La respuesta final de Castellanos es que las mujeres tenemos al alcance una forma más segura de la inmortalidad en la maternidad. Y es así que la mujer mira todos los esfuerzos del hombre en busca de la eternidad, con la misma mirada de condescendencia burlona que tiene para las inofensivas travesuras de los niños y considera sus preocupaciones trascendentales tan insignificantes como un pasatiempo que ella ni comprende, comparte o precisa.

Por su parte, los hombres que desde siempre se han considerado a sí mismos los únicos servidores de la divinidad, han visto a las mujeres como el más formidable obstáculo para el cumplimiento de su misión y la han con. verrido en el mito por el peligro que representa. La Eva por la que se pierden los paraísos, la Dalila que corta los cabellos en los que reside la fuerza, la Salomé que decapita. Y se desplazan de las voces proféticas, hasta los recursos de la "inteligencia" para inventar armas en su contra: del elemental tizón encendido de santo Tomás contra la cortesana, hasta el sistema ético de Kant que llevado hasta sus últimas consecuencias considera la maternidad como un lastre de la animalidad que es necesario destruir. La tradición cristiana que impone el celibato a sus sacerdotes impidiéndoles engendrar y exalta a la madre virgen que no haya arrastrado al hombre a sus fines propios apartándolo de sus fines específicamente masculinos, ya que mientras más acusados estén en la mujer los rasgos maternales y en el hombre la vocación cultural, la guerra de los géneros será el drama más grande como opina Schopenhauer.

\section{Conclusiones}

La cultura que conocemos ha sido creada por hombres. El testimonio histórico es irrebatible. Para Castellanos la cultura es un refugio de varones a quienes se les ha negado el don de la maternidad. Dado que la maternidad es un método tan lícito de trascendencia como la cultura. ¿Por qué, se pregunta la filósofa, no nos sentimos las mujeres arrebatadas de felicidad por ello, y por el contrario nos sentimos desconcertadas? ${ }^{15}$ Responde que la maternidad ya no constituye el camino de la trascendencia para ellas, porque se ha desvalorizado el principio femenino y lo que representa. ${ }^{16}$

Las mujeres creadoras de cultura son las exiliadas de la maternidad, tal como los hombres subliman su deseo de trascendencia en la cultura. Surge así, para nosotras, el peligro de una identificación con el estilo masculino, la

${ }^{15}$ Ibid., p. 89.

${ }^{16}$ Ibid., p. 90. 
idea de que sólo luchando con "armas de hombre" se logrará la victoria sobre la derrota de la contingencia. Victoria que por lo demás acarrea su propia desdicha, a juicio de Castellanos. La maldición bíblica del trabajo o la enfermedad (histeria a principio de siglo, depresión en nuestro tiempo). Tales son los términos de la disyuntiva. Si bien el trabajo femenino resuelve los problemas económicos más urgentes. Sin embargo, las mujeres que trabajan se enfrentan cuando no a la hostilidad, también al hecho de que los puestos están sólidamente ocupados y desempeñados por hombres y éstos no tienen la menor intención de cederlos. Finalmente, es en la escritura -concluye Rosario Castellanos- donde la mujer ha encontrado el camino más llano; hay un estilo característico de las mujeres, que tiene que ser considerado y admitido como estilo femenino, que supone, a su vez un defecto, el narcisismo. Precisamente porque todas traen a cuestas sus sentimientos maternales frustrados, esos sentimientos en cuya satisfacción las mujeres, en verdad, encuentran la inmortalidad. ${ }^{17}$ Es así que la necesidad de desbordamiento, de trascendencia, se encuentra con otro cauce, el literario, no importa si adecuado, pero posible y se derraman en él. Pero no para desbordarse sino para concentrarse en el yo, y en su "ensimismamiento". La mujer, aun si habla de la divinidad, es para expresar su relación con ella: escogiéndome a mí para revelarse, haciéndose un sitio en mi cuerpo aposentándose en él, conmoviéndolo, marcándolo, extasiándolo: y este -creo yo- es la forma del saber del alma, del alma femenina, el saber que teje Zambrano. Escrito en: "lengua materna". 18

Donde mejor se expresa este saber es en la autobiografia; en las confesiones de corte agustiniano. Es asi que las mujeres han preferido retratarse a sí mismas con amor rendido. $Y$ concluye:

[...] si es imprescindible que las mujeres escriban, cabe esperar, al menos, que lo hagan buceando cada vez más hondo en su propio ser [...] con tal impetu que sobrepase la inmediata y deleznable periferia apariencial y se hunda tan profundamente que alcance su verdadera, su hasta ahora inviolada raíz, haciendo a un lado las imágenes convencionales que de la feminidad le presenta el varón para formarse su imagen propia, su imagen basada en la personal, intransferible experiencia [...] Y que una vez tocado ese fondo (que la tradición desconoce o falsea, que los conceptos usuales no revelan) lo haga emerger a la superficie consciente y lo liberte en la expresión. ${ }^{19}$

${ }^{17}$ Ibid., p. 95.

${ }^{18}$ La lengua materna es la que aprendimos "cuerpo a cuerpo" con la madre, en cualquiera de los idiomas.

${ }^{19}$ R. Castellanos, Sobre cultura femenina, p. 97. 
Y esta es, a mi juicio, la cultura femenina, en este caso: saber del alma, pero pueden darse infinitas vertientes de tal cultura.

\section{La cultura femenina y los estudios de género}

"Cómo podemos nosotras, en tanto que mujeres, traducir nuestra experiencia en conocimiento, y en esa forma desafiar nuestra opresión sin al mismo tiempo construir una teoría sobre la opresión misma, sus causas, consecuencias y superación de ese estado de cosas".

Esta es una preocupación epistemológica, ética, política y científica. Y con base en estas consideraciones, la investigación feminista ha venido a cambiar la naturaleza de la academia durante los últimos veinte años. Los exámenes feministas de las distintas disciplinas -como lo hace Rosario Castellanos de la escritura- se iniciaron con la óptica sobre la desigualdad politica e institucional que sufren las mujeres en ese ramo, pero rápidamente progresaron las investigaciones hacia un planteamiento radical de las presuposiciones y los valores de esa área de estudio. Todo lo cual constituye la cultura femenina escrita en lengua materna, que Rosario Catellanos buscaba, como los marinos a la serpiente. Ella la avizoró con su intuición y contribuyó a ella desde su escritura.

Epílogo. "Mujer que sabe latín, ni tiene marido ni alcanza buen fin"

En este texto el tono ha cambiado, se ha vuelto ligero y poético. Recomienda a las mujeres que ... Hemos pues de crear nuestra propia imagen, la nueva identidad que nos retrate, y que dé razón de todo lo que hemos perdido. Para ello las mexicanas tenemos tres caminos: el primero, ver los problemas en profundidad; el segundo, buscar un contacto directo con la historia y realidad de México, y el tercero -el más interesante- el humor, la ironía que significa para Rosario reírse, hemos de reír, porque la risa ya sabemos es el primer testimonio de la libertad. Para ello hay que seguir la metodología específica de su ironía, no atacar los modos tradicionales con la espada desafiante, menos con el desagradable trémolo del llanto, más bien mostrar la inconsistencia ridícula de la tradición y su profunda imbecilidad. La risa es la forma más inmediata de liberación de todo lo que nos oprime: veamos algunos breves ejemplos: desafiar la pretendida furia de los patriarcas y el sacrificio inútil de las madres. Ambos representan una comedia obsoleta. Despojar al soltero del aroma apetitoso que lo envuelve. Se valúa muy alto y se vende demasiado caro. Su precio es la nulificación de su pareja, para alcan- 
zar su propia nulidad. Eliminar del vestido de la novia su nimbo glorioso, sólo son símbolos de algo muy tangible: la virginidad, que sólo tiene valor si nosotras la deseamos. Por último, la maternidad no es la "vía regia" de la santificación. Es un fenómeno predecible y controlable. Y los esposos no son ni el milagro de san Antonio, ni los monstruos de la laguna negra, son humanos cuya inferioridad daña, tanto como la nuestra. Toca a nosotras encontrar -en cada época- el lado ridículo de las costumbres. Todo esto: antes de llegar al final y componer la faz que presentemos al infinito: "Aquí estoy, al final, y aún no se que faz he de ofrecer a la muerte".

Y siendo embajadora de México en Israel murió sola, a bordo de la ambulancia que la conducía al hospital, a causa de un accidente casero sumamente misterioso. 